\title{
The Endothelial Progenitor Cell Dysfunction: The Missed Predictor of Heart Failure Outcomes?
}

\author{
Alexander E. Berezin* \\ Professor, MD, PhD, Consultant of Therapeutic Unit, Private Hospital "Vita-Center", Consultant of \\ Therapeutic Unit, Department of Internal Medicine, Medical University, Zaporozhye, Ukraine
}

*Corresponding Author: Alexander E. Berezin, Professor, MD, PhD, Consultant of Therapeutic Unit, Private Hospital "Vita-Center", Consultant of Therapeutic Unit, Department of Internal Medicine, Medical University, Zaporozhye, Ukraine, Email: aeberezin@gmail.com, g.newquist@brain2bot.com

\begin{abstract}
The objective of the review is to summarize the role of endothelial progenitor cells (EPC) dysfunction in stratification of the patients with heart failure $(H F)$.

Methods: The study was based on the review of the results of current articles depicted the diagnostic use of EPC count in HF individuals, because evidence regarding EPCs dysfunction as key player in the tissue regeneration is far controversial.

Results: EPCs are determined as a central player in the endogenous endothelial repair system. EPCs with angiopoetic activity and an ability to promote collateral vessel formation and restoration of endothelial function are widely involved into vascular reparation. Because the endothelial dysfunction strongly associates with cardiovascular $(C V)$ disease including $H F$, shaping poor function and / or decreased number of circulating EPC could be a predictor of HF-related events and CV outcomes. Recent clinical studies have shown that the EPC dysfunction may really be an early indicator of poor prognosis in patients with $\mathrm{HF}$, especially in HF individuals with preserved ejection fraction.
\end{abstract}

Conclusion: circulating EPCs in endogenous repair of impaired endothelial structure and function, deficiency of EPCs with pro-angiogenic phenotypes remains to be promising predictors of CV mortality and HF-related outcomes

Keywords: Heart Failure; Endothelium; Reparation; Progenitor Endothelial Cells; Biomarkers; Outcomes.

\section{INTRODUCTION}

Development and progression of heart failure (HF) strongly relates to microvasculature damage, endothelium dysfunction and target organ perfusion abnormalities [1]. The conceptual molecular mechanisms of shaping vascular wall cell injury base on an opinion regarding an imbalance between a damage of target cells and prevention or restore of altered structure and impaired function of them [2]. The central player in mediating vascular tissue reparation is endogenous regenerative capacity of residential cells with pluripotent activity and predominantly originated from bone-marrow stem cells and rarely from peripheral stem cells [3].

The endothelial progenitor cells (EPCs) are endothelial cell precursors with innate angiopoetic activity and an ability to promote collateral vessel formation and restore endothelial function [4]. EPCs are not only involved in the repair of the vascular wall and supporting functionality of endothelium, but they are able to release micro vesicles (MVs) with wide range of biological active substrates, i.e. active molecules, proteins, hormones, growth factors, micro-RNAs, DNAs [5, 6]. All these factors that transferred by MVs were found a component of endogenous endothelial repair system that contributes in a regulation of basic capabilities of EPCs, i.e. mobbing, differentiation, proliferation, migration, apoptosis and survival [7, 8]. Recently authors have investigated the rule of EPCs in repair, apoptosis and sequently clinical outcomes in threatening situation including acute coronary syndrome / acute myocardial infarction, early percutaneous coronary intervention, acute heart failure [9-11]. It has emphasized the EPCs act as protector of ischemic and reperfusion damage supporting repair mechanism on myocardial salvage [9]. Therefore, natriuretic peptides especially C-type of natriuretic peptide, which involve into adaptive cardiac and vascular 
remodeling and widely use biomechanical stress biomarkers with predictive value of HF-related outcomes, may mediate their effect on vascular endothelium through regulation of EPCs mobbing and differentiation [12].

There is a large body of evidence regarding that the pro- and anti-inflammatory cytokines produced by numerous immune and antigenpresenting cells in HF are co-regulators of EPC activities through supporting oxidative stress and via direct stimulation of some intracellular signal systems (Akt/STAT3) [13, 14]. On the other hand, all these pathological hyper expressed axises may affect prognosis leading to HF by different processes and mechanisms including accelerating atherosclerosis [15], shaping endothelium dysfunction and plaque instability [16]. Moreover, traditional cardiovascular (CV) risk factors especially diabetes mellitus, smocking and dyslipidemia may negatively influence on functionality and number of circulating EPCs [17-19] and thereby induce microvascular dysfunction [20].

However, poor abilities of EPCs to differentiation, migration, transformation, survival, as well as lowered number of circulating EPVs in peripheral blood in individuals at risk of $\mathrm{HF}$ and among patients with established HF with different phenotypes were determined in numerous studies [21-26]. Finally, the predictive and diagnostic role of EPC count and function in HF is not fully clear and requires to be reappraised in the future. The aim of the editorial is to summarize the knowledge regarding the role of EPCs dysfunction as a predictor of HF outcomes.

\section{THE DEFINITION OF THE EPCS}

Notably, an attribute of a progenitor cells population is ability of them to self-renewal and multiple potentialities [26]. Sorting and identification of EPC populations, i.e. hematopoietic progenitor cells, circulating endothelial cells, and culture-generated outgrowth endothelial cells, based on immunophenotyping of surface antigens that belong to various cell lines [27]. Using CD45, CD34, CD133, VEGFR (vascular endothelial growth factor receptor-2)+ EPC can be differentiated from other cell lines, while CD34+ progenitor mononuclear cells can express on the surface the same endothelial antigens [28]. Therefore, there is a subset of circulating EPCs, which is capable of in vitro differentiating into outgrowth endothelial cells with vascular regeneration abilities [29]. Interestingly, circulating endothelial cells do not belong to the cells with angiopoetic features, because they are resulting in apoptosis or cell damage [30]. However, there is a limited fraction of circulating endothelial cells that may belong to endothelial precursors, but does not express appropriate surface antigens, which allow differentiating them from mature endothelial cells using FACS protocol by flow cytometry [31]. Therefore, populations of EPCsmay distinct from the hematopoietic cell lineages by endothelial cell colony shaping. Practically, CD45-, CD31+, CD144+, and VEGFR+ are the widely used characteristics that characterize EPCs. Probably CD133 would be another antigen that could help differentiating EPCs form others, while there is no consensus of the experts regarding that. The role of different immune phenotypes of endothelial precursors localized into vascular wall or circulating in the peripheral blood is reported Figure.Finally, despite there is no final ultimate definition of immune phenotype of endothelial precursors, EPCs are frequently defined as CD45-CD31+CD144+VEGFR+ cells that contribute to neovascularization and angiogenesis directly or by secreting wide range spectrum of proangiogenic factors [32].

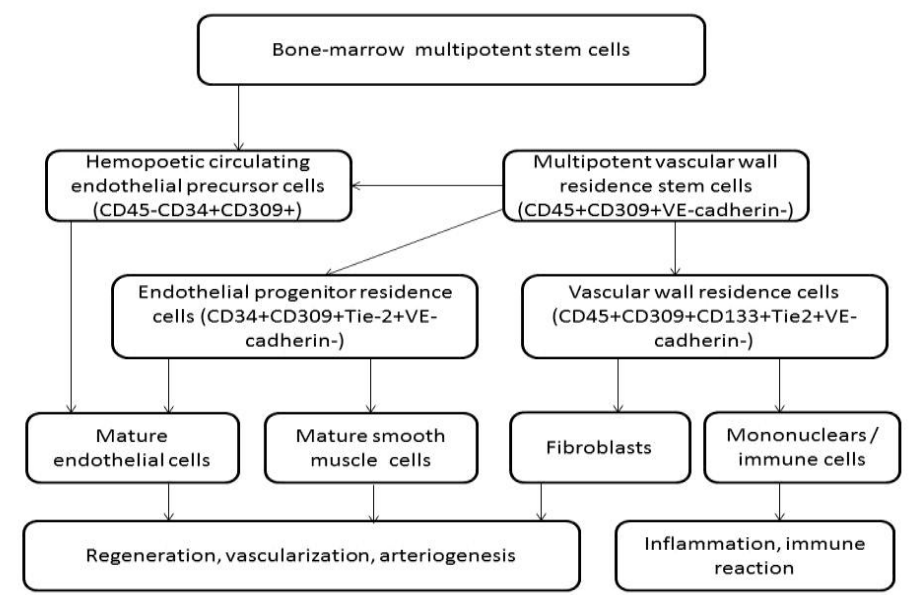

Figure. The role of different immune phenotypes of endothelial precursors 


\section{THE DEFINITION OF EPC DYSFUNCTION}

EPC dysfunction was described as a phenomenon associated with decreased number and poor function of circulating EPCs [33]. Recent clinical studies have shown that the EPCs was strongly related to metabolic comorbidities and appeared in resulting in epigenetic modification of precursors $[34,35]$. There is the suggestion that the metabolic memory phenomenon that was recently described in diabetes mellitus and even in prediabetes is a result of EPC dysfunction [20, 36]. Moreover, variability of glycated hemoglobin at early stages of diabetes mellitus development and insulin resistance are well established factors contributing to lowered number and poor function of EPCs in peripheral blood [37].

Additionally, pro-inflammatory and oxidative factors may lead to HF in subjects in absence of atherosclerotic plaque, diabetes mellitus and other metabolic diseases [38]. In this case vascular and receptorial alterations might be an attribute of microvascular dysfunction leading to HF.Probably EPCs dysfunction reflects exhausted repair capability of endogenous vascular repair potency and directly mediates microvascular abnormalities including endothelial dysfunction. Nevertheless, EPC dysfunction was recently determined in $\mathrm{HF}$ individuals in numerous clinical and observational studies [22-25]. All these facts allow grasping the EPC dysfunction in certain extent a central player in pathogenesis of HF in relation to metabolic comorbidities.

\section{EPC DYSFUNCTION AND HF-RELATED OUTCOMES}

Recent clinical trials have shown that EPC count was a significant and independent inverse predictor of $\mathrm{CV}$ mortality, newly diagnosed $\mathrm{HF}$ and HF-related outcomes [33-41].However, there are several controversies affecting immune phenotypes of EPCs and its role in prediction of HF-related events. The first controversy based on evidence regarding that the number of circulating EPCs labeled CD34+VEGF+ were found independent predictors of mortality rate in HFpEF patients [36]. Second controversy affects that the deficiency of CD45dimCD34+ VEGFR+EPCs rather associated with $\mathrm{HFpEF}$ than HFrEF [24]. Third controversy reflects lack of sufficient association between the number of circulating EPCs with different immune phenotypes (CD45dimCD34+VEGFR+ and CD45dimCD34+VEGFR+Tie2+)and traditional
$\mathrm{CV}$ risk factors [38, 39], while the decreased number and lowered function of EPCs were found in patients with diabetes mellitus, abdominal obesity, and insulin resistance [40, 41]. On the other hand, there is evidence that the natriuretic peptide plasma levels, left ventricular ejection fraction, and NYHA class of HF were known as strong predictors for depletion of CD45dimCD34 +VEGFR2+ EPC count [42]. Whether EPC dysfunction associated with decreased number and lowered function of EPCs appears prior to HF in direct link with CV risk factors or in contrast this phenomenon is essential for HF development and advance is not fully understood and requires to be investigated in details in the future. Therefore, there is uncertain whether functionality and / or count of EPC would be better predictor of HFpEF versus HFrEF, HF advance and HF-related outcomes to contemporary used natriuretic peptides, galectin-3 or soluble ST2 [43]

In conclusion, taking into consideration the role of circulating EPCs in endogenous repair of impaired endothelial structure and function, deficiency of EPCs with pro-angiogenic phenotypes remains to be promising predictors of CV mortality and HF-related outcomes.

\section{REFERENCES}

[1] Kishimoto S, Kajikawa M, Maruhashi T, Iwamoto Y, Matsumoto T, Iwamoto A, et al. Endothelial dysfunction and abnormal vascular structure are simultaneously present in patients with heart failure with preserved ejection fraction. Int J Cardiol. 2017; 231:181-187.

[2] Lu W, Li X. Vascular stem/progenitor cells: functions and signaling pathways. Cell Mol Life Sci. 2017. doi: 10.1007/s00018-017-26622 [epub ahead of print].

[3] Berezin A. Endothelial progenitor cells dysfunction and impaired tissue reparation: the missed link in diabetes mellitus development. Diabetes \& Metabolic Syndrome: Clinical Research \& Reviews. 2016 [ahead of print] Doi: 10.1016/j.dsx.2016.08.007

[4] Arderiu G, Peña E, Badimon L. Angiogenic Microvascular Endothelial Cells Release Microparticles Rich in Tissue Factor That Promotes Postischemic Collateral Vessel Formation. ArteriosclerThrombVasc Biol. 2015; 35(2):348-357.

[5] Beer L, Mildner M, Gyöngyösi M, Ankersmit HJ. Peripheral blood mononuclear cell secretome for tissue repair. Apoptosis. 2016; 21(12):1336-1353

[6] Zhang J, Ren J, Chen H, Geng Q. Inflammation induced-endothelial cells release angiogenesis associated-microRNAs into circulation by 
microparticles. Chin Med J (Engl) 2014; 127(12): 2212-2217ю

[7] Zhang Q, Shang M, Zhang M, Wang Y, Chen $\mathrm{Y}, \mathrm{Wu} \mathrm{Y}$, et al. Microvesicles derived from hypoxia/reoxygenation-treated human umbilical vein endothelial cells promote apoptosis and oxidative stress in $\mathrm{H} 9 \mathrm{c} 2$ cardiomyocytes. BMC Cell Biol. 2016; 17(1): 25 .

[8] Nomura S, Tandon NN, Nakamura T, Cone J, Fukuhara S, Kambayashi J. High-shear-stressinduced activation of platelets and microparticles enhances expression of cell adhesion molecules in THP-1 and endothelial cells. Atherosclerosis. 2001; 158:277-287

[9] Marfella R, Rizzo MR, Siniscalchi M, Paolisso P, Barbieri M, Sardu C et al. Periprocedural tight glycemic control during early percutaneous coronary intervention upregulates endothelial progenitor cell level and differentiation during acute ST-elevation myocardial infarction: effects on myocardial salvage. Int J Cardiol. 2013; 168(4):3954-62.

[10] Schmidt-Lucke C, Fichtlscherer S, Rossig L, Kamper U, Dimmeler S. Improvement of endothelial damage and regeneration indexes in patients with coronary artery disease after 4 weeks of statin therapy. Atherosclerosis. 2010; 211(1):249-54.

[11] George AL, Bangalore-Prakash P, Rajoria S, Suriano R, Shanmugam A, Mittelman A, et al. Endothelial progenitor cell biology in disease and tissue regeneration. J HematolOncol. 2011; 4(1): 24.

[12] Petretta M, Colao A, Sardu C, Scopacasa F, Marzullo P, Pivonello R. et al. NT-proBNP, IGF-I and survival in patients with chronic heart failure.Growth Horm IGF Res. 2007; 17(4):288-96.

[13] Carpintero R, Gruaz L, Brandt KJ, Scanu A, Faille D, Combes V, Grau GE, Burger D. HDL interfere with the binding of $\mathrm{T}$ cell microparticles to human monocytes to inhibit pro-inflammatory cytokine production. PLoS One. 2010; 5: e11869.

[14] Berezin A, Zulli A, Kerrigan S, Petrovic D, Kruzliak P. Predictive role of circulating endothelial-derived microparticles in cardiovascular diseases. ClinBiochem. 2015; 48(9):562-8.

[15] Gambardella J, Sardu C, Sacra C, Del Giudice C, Santulli G. Quit smoking to outsmart atherogenesis: Molecular mechanisms underlying clinical evidence.Atherosclerosis. 2017; 257: 242-245

[16] Marfella R, Ferraraccio F, Rizzo MR, Portoghese M, Barbieri M, Basilio $\mathrm{C}$ et al. Innate immune activity in plaque of patients with untreated and L-thyroxine-treated subclinical hypothyroidism. J ClinEndocrinolMetab. 2011; 96(4): 1015-20

[17] Balestrieri ML, Rizzo MR, Barbieri M, Paolisso P, D'Onofrio N, Giovane A et al. Sirtuin 6 expression and inflammatory activity in diabetic atherosclerotic plaques: effects of incretin treatment. Diabetes. 2015; 64(4):1395406

[18] Berezin AE. Metabolomics in Heart Failure Patients: Hype and Hope. Biomarkers J. 2016; 2 (3): e21-e23.

[19] Scanu A, Molnarfi N, Brandt KJ, Gruaz L, Dayer JM, Burger D. Stimulated T cells generate microparticles, which mimic cellular contact activation of human monocytes: differential regulation of pro- and antiinflammatory cytokine production by highdensity lipoproteins. J Leukoc Biol. 2008; 83: 921-927.

[20] Sardu C, Santulli G, Santamaria M, Barbieri M, Sacra C, Paolisso P. et al. Effects of Alpha Lipoic Acid on Multiple Cytokines and Biomarkers and Recurrence of Atrial Fibrillation Within 1 Year of Catheter Ablation. Am J Cardiol. 2017;119(9):1382-1386

[21] Berezin A. Metabolic memory phenomenon in diabetes mellitus: Achieving and perspectives. Diabetes MetabSyndr. 2016; 10(2 Suppl 1): S176-83.

[22] Berezin AE, Kremzer AA, Martovitskaya YV, Berezina TA, Gromenko EA. Pattern of endothelial progenitor cells and apoptotic endothelial cell-derived microparticles in chronic heart failure patients with preserved and reduced left ventricular ejection fraction. EBioMedicine. 2016; 4: 86-94.

[23] Hill J, Zalos G, Halcox J, Schenke W, Waclawiw M, Quyyumi A, Finkel T. Circulating endothelial progenitor cells, vascular function, and cardiovascular risk. $\mathrm{N}$ Engl J Med. 2003; 348: 593-600.

[24] Berezin AE, Kremzer AA, Martovitskaya YV, Samura TA, Berezina TA, Zulli A, et al. The utility of biomarker risk prediction score in patients with chronic heart failure. Int $\mathbf{J}$ ClinExp Med. 2015; 8(10): 18255-64.

[25] Berezin AE, Kremzer AA. Analysis of Various Subsets of Circulating Mononuclear Cells in Asymptomatic Coronary Artery Disease. J Clin Med. 2013, 2(3), 32-44.

[26] Patel J, Donovan P, Khosrotehrani K. Concise Review: Functional Definition of Endothelial Progenitor Cells: A Molecular Perspective. Stem Cells Transl Med. 2016; 5(10):13021306.

[27] Huizer K, Mustafa DAM, Spelt JC, Kros JM, Sacchetti A. Improving the characterization of 
endothelial progenitor cell subsets by an optimized FACS protocol. PLoS One. 2017; 12(9): e0184895.

[28] Mayani H, Alvarado-Moreno JA, FloresGuzman P. Biology of human hematopoietic stem and progenitor cells present in circulation. Arch Med Res. 2003;34(6):476-88

[29] Sieveking DP, Buckle A, Celermajer DS, Ng MK. Strikingly different angiogenic properties of endothelial progenitor cell subpopulations: insights from a novel human angiogenesis assay. J Am CollCardiol. 2008;51(6):660-668

[30] Mund JA, Shannon H, Sinn AL, Cai S, Wang $\mathrm{H}$, Pradhan KR, et al. Human proangiogenic circulating hematopoietic stem and progenitor cells promote tumor growth in an orthotopic melanoma xenograft model. Angiogenesis. 2013;16(4):953-62

[31] Schmidt-Lucke C, Fichtlscherer S, Aicher A, Tschope C, Schultheiss HP, Zeiher AM, et al. Quantification of circulating endothelial progenitor cells using the modified ISHAGE protocol. PLoS One. 2010;5(11):e13790

[32] Fadini GP, Losordo D, Dimmeler S. Critical reevaluation of endothelial progenitor cell phenotypes for therapeutic and diagnostic use. Circ Res. 2012; 110(4): 624-37.

[33] Rigato M, Fadini GP. Circulating stem/progenitor cells as prognostic biomarkers in macro- and microvascular disease. A narrative review of prospective observational studies. Curr Med Chem. 2017. doi: 10.2174/0929867324666170920154020.

[34] Nozaki T, Sugiyama S, Koga H, Sugamura K, Ohba K, Matsuzawa Y. et al. Significance of a multiple biomarkers strategy including endothelial dysfunction to improve risk stratification for cardiovascular events in patients at high risk for coronary heart disease. J Am CollCardiol. 2009; 54:601-8.

[35] Koller L, Hohensinner P, Sulzgruber P, Blum S, Maurer G, Wojta J, et al. Prognostic relevance of circulating endothelial progenitor cells in patients with chronic heart failure. ThrombHaemost. 2016; 116(2): 309-16.
[36] SammanTahhan A, Hammadah M, Sandesara PB, Hayek SS, Kalogeropoulos AP, Alkhoder $A$, et al. Progenitor Cells and Clinical Outcomes in Patients With Heart Failure. Circ Heart Fail. 2017; 10(8).

[37] Berezin AE, Kremzer AA. Content of circulating endothelial progenitor cells in patients with chronic ischemic heart failure with preserved left ventricular ejection fraction. Kardiologiia. 2015; 55(1):14-22.

[38] Marfella R, Barbieri M, Sardu C, Rizzo MR, Siniscalchi M, Paolisso P et al. Effects of $\alpha$ lipoic acid therapy on sympathetic heart innervation in patients with previous experience of transient takotsubo cardiomyopathy. $\mathbf{J}$ Cardiol. 2016;67(2):153-61.

[39] Kachamakova-Trojanowska N, BukowskaStrakova K, Zukowska M, Dulak J, Jozkowicz A. The real face of endothelial progenitor cells - Circulating angiogenic cells as endothelial prognostic marker? Pharmacol Rep. 2015;67(4): 793-802.

[40] Berezin AE, Kremzer AA, Berezina TA, Martovitskaya YV, Gronenko EA. Data regarding association between serum osteoprotegerin level, numerous of circulating endothelial-derived and mononuclear-derived progenitor cells in patients with metabolic syndrome. Data Brief. 2016; 8: 717-22.

[41] Berezin AE, Kremzer AA, Samura TA, Berezina TA, Martovitskaya YV. Serum uric Acid predicts declining of circulating proangiogenic mononuclear progenitor cells in chronic heart failure patients. J CardiovascThorac Res. 2014; 6(3):153-62.

[42] Berezin AE, Kremzer AA. Relationship between circulating endothelial progenitor cells and insulin resistance in non-diabetic patients with ischemic chronic heart failure. Diabetes MetabSyndr. 2014; 8(3): 138-44.

[43] Katsanos S, Mavrogenis AF, Kafkas N, Sardu C, Kamperidis V, Katsanou P et al. Cardiac Biomarkers Predict 1-Year Mortality in Elderly Patients Undergoing Hip Fracture Surgery.Orthopedics. 2017;40(3):e417-e424

Citation: Alexander E. Berezin, The Endothelial Progenitor Cell Dysfunction: the Missed Predictor of Heart Failure Outcomes?. ARC Journal of Cardiology. 2017; 3(2):1-5. doi: dx.doi.org/10.20431/2455-5991. 0302001

Copyright: (c) 2017 Authors. This is an open-access article distributed under the terms of the Creative Commons Attribution License, which permits unrestricted use, distribution, and reproduction in any medium, provided the original author and source are credited. 